\title{
Optimal Dose of Thymoglobulin for Induction Therapy in High Risk Kidney Transplant Recipients
}

\author{
Yaerim Kim, M.D. ${ }^{1,2}$, Seong Sik Kang, M.D. ${ }^{1,2}$, Woo Yeong Park, M.D. ${ }^{1,2}$, Kyubok Jin, M.D. ${ }^{1,2}$, \\ Sung Bae Park, M.D. ${ }^{1,2}$, Ui Jun Park, M.D. ${ }^{2,3}$, Hyoung Tae Kim, M.D. ${ }^{2,3}$ and Seungyeup Han, M.D. ${ }^{1,2}$ \\ Department of Internal Medicine, Keimyung University School of Medicine', Keimyung University Kidney Institute ${ }^{2}$, \\ Department of Surgery, Keimyung University School of Medicine ${ }^{3}$, Daegu, Korea
}

Background: Thymoglobulin has been used for induction therapy to prevent acute rejection and delayed graft function (DGF) in kidney transplant patients. However, the usual dose of thymoglobulin is considered to be related with frequent infection. We compared the efficacy and safety of low-dose thymoglobulin to high-dose treatment in high risk recipients with kidney transplantation.

Methods: Twenty-one kidney transplant recipients underwent induction treatment with thymoglobulin and were divided into two groups: patients treated with low-dose $(<6.0 \mathrm{mg} / \mathrm{kg})$ and high-dose thymoglobulin $(\geq 6.0 \mathrm{mg} / \mathrm{kg})$. All patients showed one or more risk factors for acute rejection or DGF. The risk factors were re-transplantation, recipient or donor age over 60 years, human leukocyte antigen full mismatch, and panel-reactive antibody more than $50 \%$. We compared incidence of acute rejection, infection, hematologic complications, and graft survival between two groups.

Results: The demographic characteristics of the two groups were comparable. Mean follow-up duration was $11.9 \pm 4.3$ months, and cumulative thymoglobulin dosage was $6.3 \pm 1.6 \mathrm{mg} / \mathrm{kg}$. The incidence rates of acute antibody-mediated rejection (AMR), DGF and infectious events as cytomegalovirus disease, or urinary tract infection were not significantly different between the two groups. Neutropenia occurred more frequently in the high-dose thymoglobulin group, but there was no statistically significant difference. The rate of graft loss were similar between the two groups.

Conclusions: There were no differences in graft survival, infectious disease, and hematologic problems between the two groups. We suggest to lower the dose of thymoglobulin to less than $6 \mathrm{mg} / \mathrm{kg}$ for prevent acute AMR and DGF in high risk patients.

Key Words: Immunosuppressive agents, Kidney transplantation, Thymoglobulin 중심 단어: 면역억제제, 신장이식, 치모글로불린

\section{INTRODUCTION}

Thymoglobulin is one of the most widely used induction immunosuppressant in kidney transplantation. It was better than basiliximab on acute rejection and graft survival rate

Received March 8, 2016

Revised May 13, 2016

Accepted May 19, 2016

Corresponding author: Seungyeup Han

Department of Internal Medicine, Keimyung University School of Medicine, 56 Dalseong-ro, Jung-gu, Daegu 41931, Korea

Tel: 82-53-250-7399, Fax: 82-53-253-7976

E-mail: hansy@dsmc.or.kr by 5 and 10 years follow-up(1,2). Kidney transplantation is the best treatment for chronic kidney disease, and it has been performed increasingly in patients with high risk for acute antibody-mediated rejection (AMR) and delayed graft function (DGF). Brennan et al.(3) presented that thymoglobulin is better than basiliximab for high risk patients, reduced acute rejection rate and severity(3-5). However the usual dose of thymoglobulin $(7 \sim 10 \mathrm{mg} / \mathrm{kg})$ may contribute to increase risk of infectious disease or malignancy(6). Even low-dose thymoglobulin reduced risk for acute rejections and maintained better kidney function by 3 and 5 years fol- 
low-up than basiliximab(7). There are some studies to find out efficacy and safety of low-dose thymoglobulin, but there is no consensus for optimal dose, especially for high risk patients yet(7,8). In this study, we suggest the optimal dose of thymoglobulin for high risk patients to prevent acute rejection or DGF include patients who transplanted from extended criteria donor.

\section{MATERIALS AND METHODS}

The report is retrospective study of kidney transplantation performed in Keimyung University Dongsan Medical Center from September 2013 to October 2014. Twenty-six patients received thymoglobulin as induction therapy, 21 have a risk factor for acute AMR or DGF. Minimum follow-up duration was 3 months. The risk factors were defined as re-transplantation, donor or recipient age over 60, human leukocyte antigen (HLA) full mismatch, panel-reactive antibody (PRA) over $50 \%$. We divided our patients to two groups:

Table 1. Comparison of demographic characteristics by thymoglobulin dosage

\begin{tabular}{|c|c|c|c|}
\hline Characteristic & $\begin{array}{c}\text { Low-dose } \\
\text { group }^{\text {a }}(n=8)\end{array}$ & $\begin{array}{l}\text { High-dose } \\
\text { group }^{b}(n=13)\end{array}$ & $P$ value \\
\hline $\begin{array}{l}\text { Thymoglobulin dose } \\
(\mathrm{mg} / \mathrm{kg})\end{array}$ & $4.64 \pm 0.22$ & $7.31 \pm 0.26$ & 0.000 \\
\hline $\begin{array}{l}\text { Follow-up duration } \\
\text { (mo) }\end{array}$ & $9.8 \pm 1.53$ & $13.2 \pm 1.06$ & 0.074 \\
\hline Recipient age (yr) & $55.0 \pm 2.24$ & $50.6 \pm 3.62$ & 0.586 \\
\hline Donor age (yr) & $49.1 \pm 3.41$ & $43.4 \pm 3.63$ & 0.231 \\
\hline Recipient male, sex & $2(25.0)$ & $7(53.8)$ & 0.367 \\
\hline Deceased donor & $7(87.5)$ & $11(84.6)$ & 1.000 \\
\hline DSA $(+)$ & $3(42.9)$ & $4(57.1)$ & 1.000 \\
\hline Re-transplantation & $3(37.5)$ & $3(23.1)$ & 0.631 \\
\hline Recipient age $>60 \mathrm{yr}$ & $2(25.0)$ & $3(23.1)$ & 1.000 \\
\hline Donor age $>60 \mathrm{yr}$ & 0 & $2(15.4)$ & 0.505 \\
\hline HLA full mismatch & 0 & $4(30.8)$ & 0.131 \\
\hline PRA I or II $>50 \%$ & $6(75.0)$ & $5(38.5)$ & 0.183 \\
\hline PRA I $>50 \%$ & $2(25.0)$ & $4(30.8)$ & 1.000 \\
\hline PRA II $>50 \%$ & $4(50.0)$ & $2(15.4)$ & 0.146 \\
\hline $\begin{array}{l}\text { Serum creatinine } \\
(\mathrm{mg} / \mathrm{dL})\end{array}$ & $1.27 \pm 0.21$ & $1.45 \pm 0.39$ & 0.885 \\
\hline
\end{tabular}

Data are presented as mean \pm SD or number $(\%)$.

Abbreviations: DSA, donor specific antibody; HLA, human leukocyte antigen; PRA, panel-reactive antibody.

${ }^{a}$ Low-dose group: thymoglobulin $<6.0 \mathrm{mg} / \mathrm{kg}$; ${ }^{\mathrm{b}}$ High-dose group: thymoglobulin $>6.0 \mathrm{mg} / \mathrm{kg}$. group $\mathrm{A}$, the patients induced with thymoglobulin $<6.0$ $\mathrm{mg} / \mathrm{kg}(\mathrm{n}=8)$; group $\mathrm{B}$, the patients induced with thymoglobulin $\geq 6.0 \mathrm{mg} / \mathrm{kg}(\mathrm{n}=13)$ (Table 1). Maintenance immunosuppressant regimens were tacrolimus, mycophenolate mofetil, and prednisolone. Calcineurin inhibitor was started within 5 days after transplantation. All patients received valganciclovir and trimethoprim/sulfamethoxazole to prevent cytomegalovirus (CMV) and Pneumocystis jirovecii pneumonia infection.

We compared the incidence of acute AMR and DGF, CMV infection, urinary tract infection, lymphocele, neutropenia, thrombocytopenia, and graft failure. Acute AMR was confirmed by kidney biopsy and DGF was defined as the conditions which require dialysis within first week after transplantation. CMV infection was defined as which require treatment and diagnosed by quantitative polymerase chain reaction. Urinary tract infection was defined as a positive result of culture and needed treatment. Lymphocele was defined as needed drainage after transplantation. Neutropenia was defined as leukocyte less than $4,000 / \mathrm{mL}$, thrombocytopenia as platelet less than $100,000 / \mathrm{mL}$ within 3 weeks after transplantation. Graft loss means that patients need maintenance dialysis.

The statistical analysis was done by SPSS ver. 21.0 (IBM Co., Armonk, NY, USA). Continuous variables were expressed as mean \pm standard deviation, norminal variables were expressed as number and percentage. Fisher exact test and Mann-Whitney test were used to analyze differences of two groups. This study was approved by the Institutional Review Boards of Keimyung University School of Medicine (2015-11-026).

\section{RESULTS}

The baseline demography was similar between two groups. There were no statistical differences between two groups in the number of both recipient's and donor's age over 60 years, and the number of deceased donor. The rate of HLA full mismatch was higher in group B than group A, but there was no statistical significance. Both groups were similar in the number of patients with PRA $>50 \%$, DSA (+). Re-transplantation rates were similar between two groups; there was one case of third transplantation in group A. The 
mean values of finally checked serum creatinine between two groups had statistical indifference (Table 1).

Group A presented lower incidence of DGF and higher in the incidence of AMR than group B, but there were no significant differences. There were no differences in CMV infection and urinary tract infection. There were eight cases of CMV gastritis (4 vs. 4), one CMV nephritis (group B). There were three patients who had presented CMV infection twice or more (1 vs. 2). In group A, there was one miliary tuberculosis. In addition, there was one pulmonary tuberculosis with central nervous system tuberculoma in group B. One BK virus infection was presented as BK viremia with BK nephropathy that occurred in group A. There was no statistical difference in overall infectious disease between two groups. Lymphocele was occurred only one case which is group B. Hematologic complications including neutropenia and thrombocytopenia occurred similarly between two groups. The serious adverse events such as serum sickness and delayed cardiopulmonary reaction did not occur in both groups. There was one case of graft loss in group B (Table 2). The cause of graft loss was uncontrolled rejection combined with infection.

\section{DISCUSSION}

Among patients with high risk for acute AMR and DGF, thymoglobulin is better than basiliximab in diverse as-

Table 2. Comparison of outcomes between low-dose and high-dose groups

\begin{tabular}{|c|c|c|c|}
\hline Variable & $\begin{array}{l}\text { Low-dose } \\
\text { group }^{\text {a }}(\mathrm{n}=8)\end{array}$ & $\begin{array}{l}\text { High-dose } \\
\operatorname{group}^{b}(n=13)\end{array}$ & $P$-value \\
\hline Delayed graft function & $1(12.5)$ & $5(38.5)$ & 0.336 \\
\hline $\begin{array}{l}\text { Antibody-mediated } \\
\text { rejection }\end{array}$ & $3(37.5)$ & $1(7.7)$ & 0.253 \\
\hline $\begin{array}{l}\text { Cytomegalovirus } \\
\text { infection }\end{array}$ & $4(50.0)$ & $5(38.5)$ & 0.673 \\
\hline Urinary tract infection & $2(25.0)$ & $4(30.8)$ & 1.000 \\
\hline Lymphocele & 0 & $1(7.7)$ & 1.000 \\
\hline Neutropenia & $5(62.5)$ & $11(84.6)$ & 0.325 \\
\hline Thrombocytopenia & $3(37.5)$ & $4(30.8)$ & 0.557 \\
\hline Graft loss & 0 & $1(7.7)$ & 1.000 \\
\hline
\end{tabular}

Data are presented as number $(\%)$.

${ }^{\text {a } L o w-d o s e ~ g r o u p: ~ t h y m o g l o b u l i n ~}<6.0 \mathrm{mg} / \mathrm{kg}$; ${ }^{\text {b }} \mathrm{High}$-dose group: thymoglobulin $\geq 6.0 \mathrm{mg} / \mathrm{kg}$. pects (1-5). But basiliximab is preferred to thymoglobulin because full dose thymoglobulin $(7 \sim 10 \mathrm{mg} / \mathrm{kg})$ was associated with higher rates of infectious disease or hematologic complications. In most cases, infection rates were high in full dose thymoglobulin group, so we designed cut off level of thymoglobulin by $6 \mathrm{mg} / \mathrm{kg}$ and compared acute AMR, DGF, infection, hematologic complication, and graft survival between two groups(6).

There were no statistical differences in acute AMR and DGF between two groups. Acute rejections were more frequent in low-dose thymoglobulin group because there were more patients with high PRA or re-transplantation in group A. DGF were more frequent in group $B$ because there were more cases with extended criteria donors.

Use of thymoglobulin more than $7 \mathrm{mg} / \mathrm{kg}$ has been associated with more frequent infectious complications(6). Although divided by $6 \mathrm{mg} / \mathrm{kg}$, there were no significant differences between two groups in this study. CMV infections occurred more frequently in our study irrespective of thymoglobulin dose, compared to usual incidence. Especially, recurrent CMV infections were more frequent in high-dose thymoglobulin group. It seems to need more intensive prophylaxis to prevent CMV infection in the patient treated with thymoglobulin by induction therapy(9).

By using low-dose thymoglobulin, we could not observe differences in acute rejection and graft loss compare to high-dose thymoglobulin. It suggests that low-dose thymoglobulin is not inferior to high-dose on the effect of defending an acute rejection and DGF. We recommend the optimal dose of thymoglobulin to be less than $6 \mathrm{mg} / \mathrm{kg}$.

We recognized that our study has several limitations. The result was seems to be carried out with relatively small number of patients, which limits its statistical power to compare the effect of low-dose thymoglobulin with high-dose thymoglobulin in high risk patients. In addition, the period for following up the patients' course were not sufficient. It would be innovative to identify the optimal dose of thymoglobulin if the large study is performed with long term follow-up.

\section{CONCLUSION}

Low dose thymoglobulin was effective as much as high 
dose for prevention of acute rejection and DGF in high risk patients. The incidences of complications like infection and hematologic problem were not different between two groups. Although we need more study to lower the dose of thymoglobulin, we can suggest that less than $6 \mathrm{mg} / \mathrm{kg}$ of thymoglobulin is efficient for prevention of acute rejection and DGF in high risk patients.

\section{REFERENCES}

1) Brennan DC, Schnitzler MA. Long-term results of rabbit antithymocyte globulin and basiliximab induction. $\mathrm{N} \mathrm{Engl}$ J Med 2008;359:1736-8.

2) Lentine KL, Schnitzler MA, Xiao H, Brennan DC. Long-term safety and efficacy of antithymocyte globulin induction: use of integrated national registry data to achieve ten-year follow-up of 10-10 study participants. Trials 2015;16:365.

3) Brennan DC, Daller JA, Lake KD, Cibrik D, Del Castillo D; Thymoglobulin Induction Study Group. Rabbit antithymocyte globulin versus basiliximab in renal transplantation. N Engl J Med 2006;355:1967-77.

4) Chen G, Gu J, Qiu J, Wang C, Fei J, Deng S, et al. Efficacy and safety of thymoglobulin and basiliximab in kidney transplant patients at high risk for acute rejection and delayed graft function. Exp Clin Transplant 2013;11:310-4.

5) Sancho Calabuig A, Gavela Martinez E, Kanter Berga J, Beltran Calatan S, Avila Bernabeu AI, Pallardo Mateu LM. Safety and efficacy of induction treatment with low thymoglobulin doses in kidney transplantation from expanded-criteria donors. Transplant Proc 2015;47:50-3.

6) Clesca P, Dirlando M, Park SI, Garcia R, Ferraz E, Pinheiro-Machado PG, et al. Thymoglobulin and rate of infectious complications after transplantation. Transplant Proc 2007;39:463-4.

7) Laftavi MR, Alnimri M, Weber-Shrikant E, Kohli R, Said $\mathrm{M}$, Patel S, et al. Low-dose rabbit antithymocyte globulin versus basiliximab induction therapy in low-risk renal transplant recipients: 8-year follow-up. Transplant Proc 2011;43:458-61.

8) Laftavi MR, Patel S, Soliman MR, Alnimri M, Kohli R, Said $\mathrm{M}$, et al. Low-dose thymoglobulin use in elderly renal transplant recipients is safe and effective induction therapy. Transplant Proc 2011;43:466-8.

9) Luan FL. Six-month low-dose valganciclovir prophylaxis in cytomegalovirus $\mathrm{D}+\mathrm{R}$ - kidney transplant patients receiving thymoglobulin induction. Transplant Proc 2013;45: 175-7. 